\section{An attempt to increase technological capabilities of laboratory vibratory mills by changing the construction of chamber}

\author{
Paweł Tomach \\ AGH University of Science and Technology, Poland
}

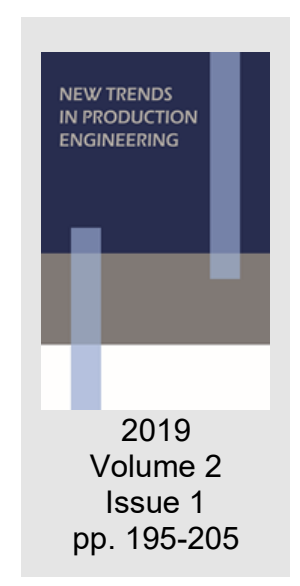

Date of submission to the Editor: 05/2019

Date of acceptance by the Editor: 07/2019

\title{
INTRODUCTION
}

Vibratory mills are classified in the group of high energy mills, which are characterized by a high potential of industrial use - much wider than the most widely used and best known gravity ball mills. This article is related to the increase of the technological capabilities of vibratory mills which are used in all industries - ranging from the mining industry to the pharmaceutical industry where on a global scale, several dozen billion $\mathrm{Mg}$ of grained materials are annually produced for all types of mills.

In the vast majority of industrial constructions of vibratory mills, their chambers are introduced into a vibrating motion by means of inertial vibrators, however, the vibration is induced in a kinematic manner (in laboratory and industrial mills with a capacity below $5 \mathrm{Mg}$ per hour). The kinematic extortion of the vibrating motion results in the complication of the mill structure, but it provides stable parameters of the vibrating motion, which also apply in vibrating crushers (Mazur 2017a; 2017 b) or vibratory granulator (Feliks, 2015).

A significant limitation in the construction of tubular vibratory mills with quasicircular trajectory of vibration amplitude with a capacity above a few $\mathrm{Mg} / \mathrm{h}$, as well as the possibility to obtain in these mills grinding product with the very fine, colloidal and nano-grained materials, is a non-linear and very unfavourable drop in the speed of the grinding process along with an increase in the chamber diameter (Drzymała et al., 1992; Sidor, 2005). This phenomenon is the result of a decrease in the kinetic energy of grinding media in the direction of the geometrical axis of the chamber.

One of the construction paths for the new vibratory mills, with high efficiency and simplified structure, equipped with chambers of over $1000 \mathrm{~mm}$ diameters and reduced or completely eliminated low energy zone of the grinding media, is the use of a possibly small volume element in the chamber, the high stiffness, which connected with the chamber would vibrate with it and transfer energy to the grinding media that contact the element (Tomach, 2016; 2017a; 2017b; Sidor \& Tomach, 2010; 2011; 2013). 
The article presents selected results of experimental studies carried out in the laboratory vibratory mills: periodic and kinematic operation forcing vibrating motion and continuous operation, in which inertial vibration of the vibrating motion was used.

\section{TEST BENCHES}

\section{Vibratory mill of periodic operation}

The mechanical scheme and the virtual model of the test bench of a vibratory mill with periodic operation are presented in Figure 1, while Table 1 presents its basic technical parameters.

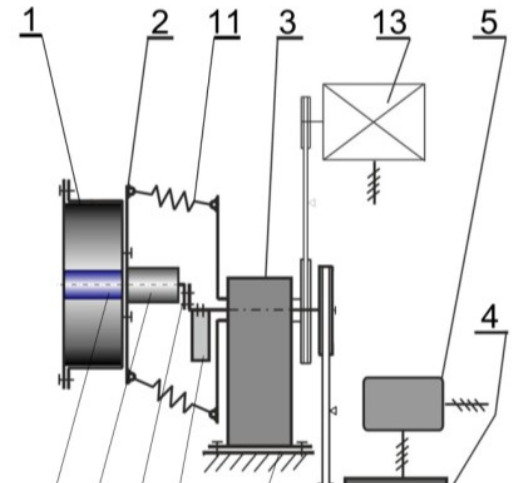

$\underline{10} \underline{9} \underline{8} 7$

$\underline{6}$ .

Fig. 1 Periodic working vibrating mill test stand mode

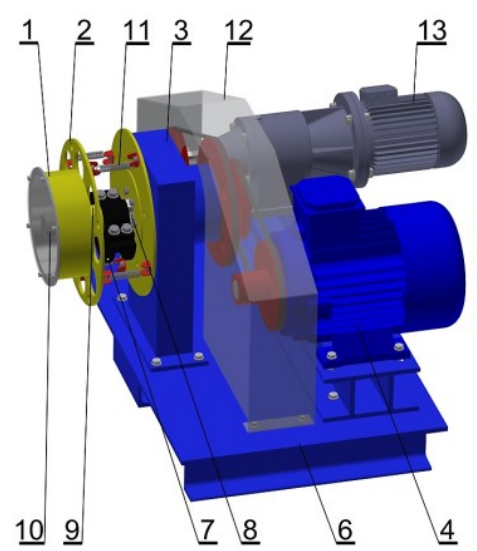

1 - chamber, 2 - chamber handle, 3 - drive unit, 4 - motor of vibrator, 5 - control and power supply, 6 - base, 7 - weight, 8 - eccentric shaft (vibrator), 9 - chamber bearing, 10 - additional cylindrical element, 11 - spring, 12 - drive cover, 13 - drive of chamber rotation

Source: (not used in the study)

Table 1 The basic technical parameters of the test bench of a vibratory mill

\begin{tabular}{|l|c|c|}
\hline \multicolumn{1}{|c|}{ Name of the parameter } & Unit & Value \\
\hline Amplitude of vibrations in the chamber & $\mathrm{mm}$ & $3 \div 14$ \\
\hline Vibration frequency of the chamber & $\mathrm{Hz}$ & $4 \div 18$ \\
\hline The degree of the filling of the chamber & $\%$ & $10 \div 90$ \\
\hline Motor power of the vibrator drive & $\mathrm{kW}$ & 3.5 \\
\hline
\end{tabular}

During the experimental studies in a periodical mill, two types of intensifying elements with different diameters have been used - with a diameter $48 \mathrm{~mm}$ for a chamber with an inner diameter of $210 \mathrm{~mm}$, and $75 \mathrm{~mm}$ for a chamber with an inner diameter of $310 \mathrm{~mm}$. Placing a cylindrical element in the chamber resulted in a reduction in the volume of the working chamber. The experimental studies have been carried out in steel chambers whose parameters, together with the given percentage change in the working volume of the chamber (caused by the use of an intensifying element), are presented in Table 2.

Table 1 Parameters of chambers with inner diameter of $210 \mathrm{~mm}$ used during the studies

\begin{tabular}{|ll|c|c|c|c|}
\hline \multicolumn{2}{|c|}{ Type and symbol of the chamber } & „S” & „A" & „D310S” & „D310B” \\
\hline Internal diameter of the chamber & $\mathrm{mm}$ & 210 & 210 & 310 & 310 \\
\hline Diameter of the intensifying element & $\mathrm{mm}$ & - & 48 & - & 75 \\
\hline Working volume of the chamber & $\mathrm{dm}^{3}$ & 2.25 & 2.09 & 5.00 & 4.68 \\
\hline $\begin{array}{l}\text { The share of the active volume } \\
\text { of the chamber }\end{array}$ & $\%$ & 100 & 93 & 100 & 94 \\
\hline
\end{tabular}


In order to increase the readability of this article in its subsequent part, in accordance with Table 2, a nomenclature based on abbreviated chamber designations („S”, „A”, „D31S”, „D310B”) was adopted. The view of the chambers with an inner diameter of $210 \mathrm{~mm}$ described above, is shown in Figure 2.

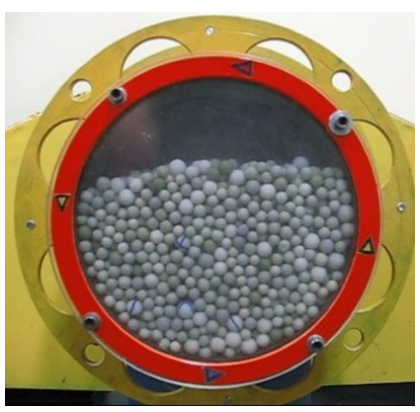

Chamber "S"

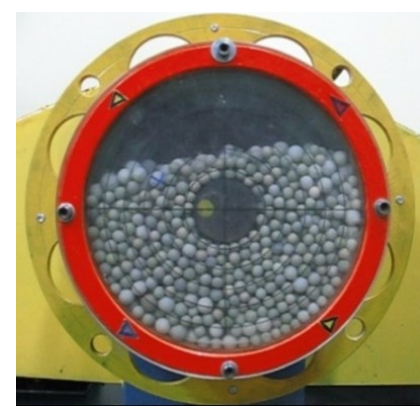

Chamber "A"

Fig. 2 View of the chambers with an internal diameter of $210 \mathrm{~mm}$ used during the studies

\section{Continuous vibratory mill}

The test stand of a laboratory continuous vibratory mill, its virtual model, is shown in Figure 3. This mill has an inertial force and a quasi-circular or elliptical trajectory of the vibration amplitude of the chamber (depending on the way the drive is implemented). The studies were carried out in a cylindrical steel chamber with an internal diameter of $205 \mathrm{~mm}$ and a capacity of $10 \mathrm{dm}^{3}$ in the classic version ("K" chamber) and with an intensifying element with a diameter of $48 \mathrm{~mm}$ ("W" chamber).

During the studies, a vibrator driven from two engines using synchronized cardan shafts was used to introduce the working set into a vibrating motion, which ensured a quasi-circular vibration trajectory of the working unit in which the chamber is located.

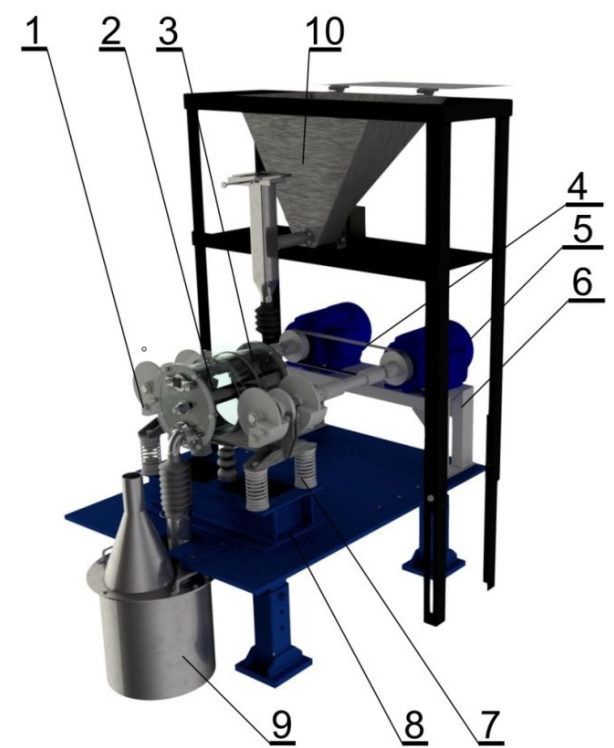

Fig. 3 Continuous working vibrating mill test stand model 1 - vibrator, 2 - chamber, 3 - intensifying element, 4 - gear synchronizing vibrator shafts, 5 - motor, 6 - motor frame, 7 - spring support, 8 - mill frame, 9 - collection of the grinding product, 10 - hopper with a screw feeder 
The basic parameters and capabilities of the test stand:

- operation of the continuous mill with the possibility of grinding in the air and liquid environment,

- efficiency of the mill (dry weight) $0.5 \div 50 \mathrm{~kg} / \mathrm{h}$ - graining of the feed below 6.0 $\mathrm{mm}$,

- chamber capacity $10 \mathrm{dm}^{3}$,

- drive: two $1.5 \mathrm{~kW}$ motors with synchronous rate of rotation $1000 \mathrm{rpm}$,

- rated speed of the inertia vibrator $950 \mathrm{rpm}$,

- the vibration amplitude of the working set is adjustable in the range of $3 \div 8$ $\mathrm{mm}$,

- the mass of the mill stand without grinding media is about $380 \mathrm{~kg}$,

- the mill has the opportunity to work on the vibration trajectories: quasi-circular or elliptical,

- the chamber aeration change range is carried out by a stepless modification in the fan motor power of the chamber aeration system - without measuring the aeration air flow rate.

In order to determine the quality of the milling process, it is necessary to assess the graining of the milling product. The devices used to analyze the grain composition of powders, providing fast and burdened with a relatively low measurement error, are laser granulometers. The analyses of graining of ground materials were made in a LAU-15 laser granulometer (Tomach, 2016).

The presented results of the measurement of graining of the grinding product were given as average values. The mean estimate errors were determined using the Student's t-distribution at the 0.05 confidence level. The total maximum error value (sampling error - milling error and grain size determination error by the LAU 15 laser granulometer) was: $\pm 4 \%$ for grain size d 50 to $\pm 16 \%$ for grain size d97.

\section{CHARACTERISTICS OF THE MATERIAL USED FOR THE STUDIES}

A significant element of experimental studies is the selection of the appropriate model material, whose stable physical properties allow to obtain reproducible results, burdened with the smallest possible error. Therefore, as a model material for testing the grinding process, quartz sand - grade I glass from KiZPPS Osiecznica Sp. z o.o. with a grain size of $98.8 \%$ below $0.5 \mathrm{~mm}$, was used. This material was chosen as a model material due to its high grain stability, high purity and chemical resistance, non-hygroscopic properties and its widespread use in milling processes research (Tomach, 2016).

\section{EXPERIMENTAL RESEARCH IN A VIBRATORY MILL OF PERIODIC OPERATION}

The following technological parameters were adopted for milling studies in a mill of periodic operation:

- chamber filling level $b=0.80[-]$ the most favorable for the classic chamber,

- vibration amplitude $A=5.0 \mathrm{~mm}$, 
- vibration frequency $\mathrm{f}=16 \mathrm{~Hz}$,

- grinding media set $\varnothing 157.5 \mathrm{~mm}$.

The values measured as the criterion for the quality of the milling process were:

- control grain size d97, $\mu \mathrm{m}$,

- control grain size $d_{50}, \mu \mathrm{m}$,

- mill capacity, $\mathrm{kg} / \mathrm{h}$.

The variable parameter adopted during the quartz sand milling process was milling time. To determine the kinetics of grinding, the following times were adopted: $2.5 \mathrm{~min} ; 5.0 \mathrm{~min} ; 10.0 \mathrm{~min}$ and $20.0 \mathrm{~min}$.

Figure 4 below presents the influence of grinding time on the grain size control dimension $\mathrm{d}_{97}$ and in Figure 5 on the grain size control dimension $\mathrm{d}_{50}-$ depending on the type of chamber used.

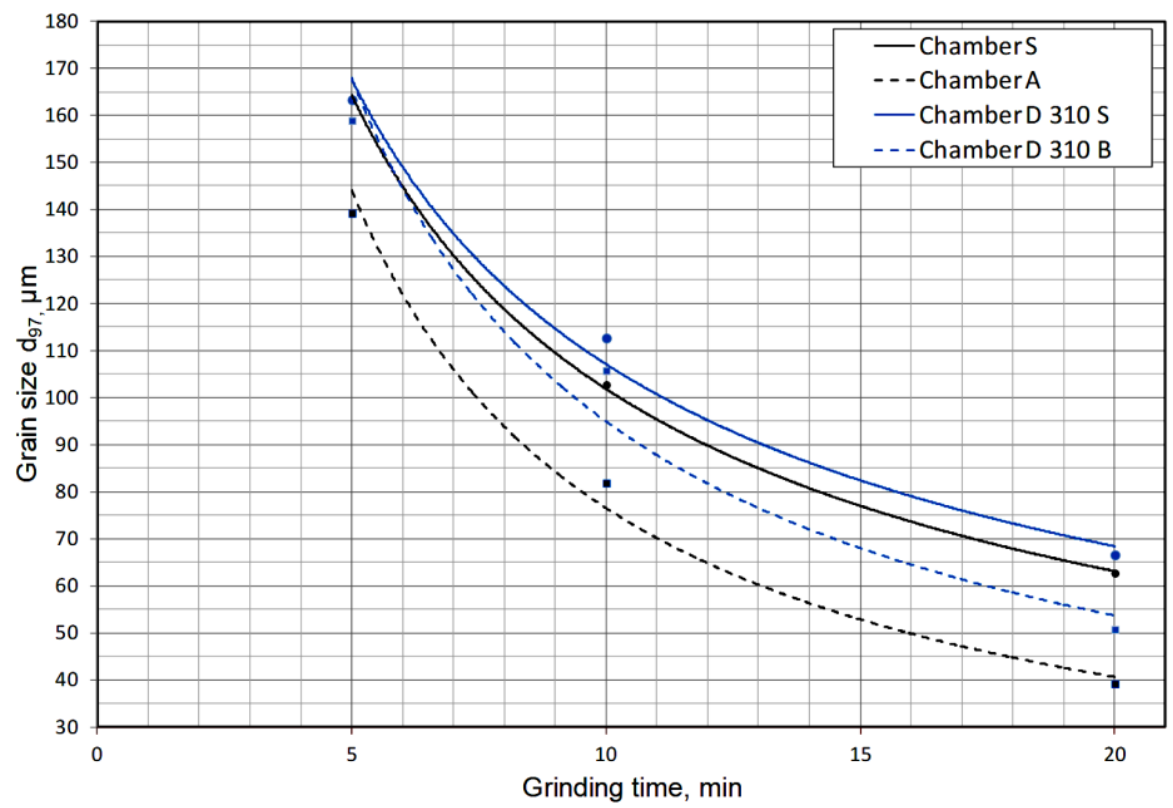

Fig. 4 Influence of grinding time on the grain size control dimension d97 for chambers: "S", "A", "D 310 S" and "D 310 B"

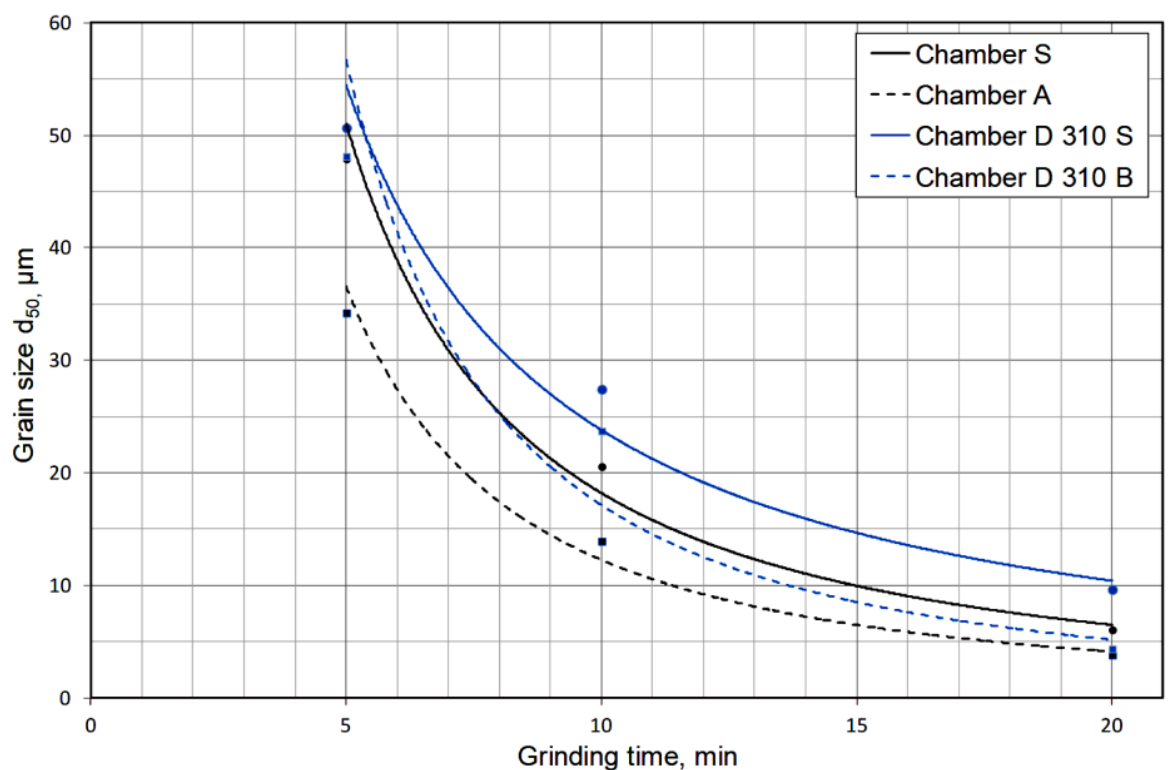

Fig. 5 Influence of grinding time on the grain size control dimension d $d_{50}$ for chambers: "S", "A", "D 310 S" and "D 310 B" 
Figures 6 and 7 present the influence of the type of chamber used on obtaining the unit capacity of the mill for grain size $d_{97}=70 \mu \mathrm{m}$ (Figure 6) and $d_{50}=10 \mu \mathrm{m}$ (Figure 7).

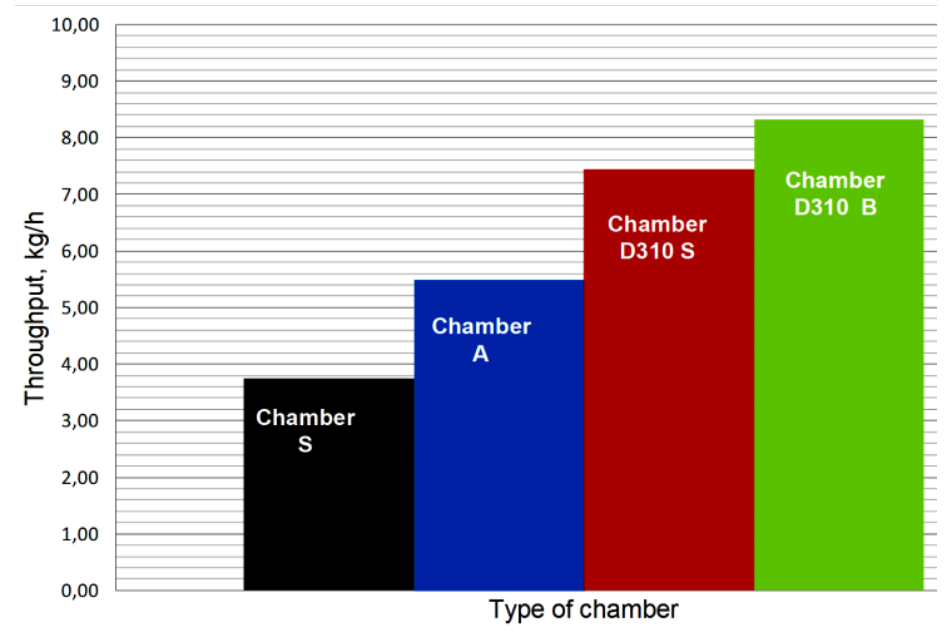

Fig. 6 Influence of the type of chamber used on obtaining the unit capacity of the mill for grain size $d_{97}=70 \mu \mathrm{m}$

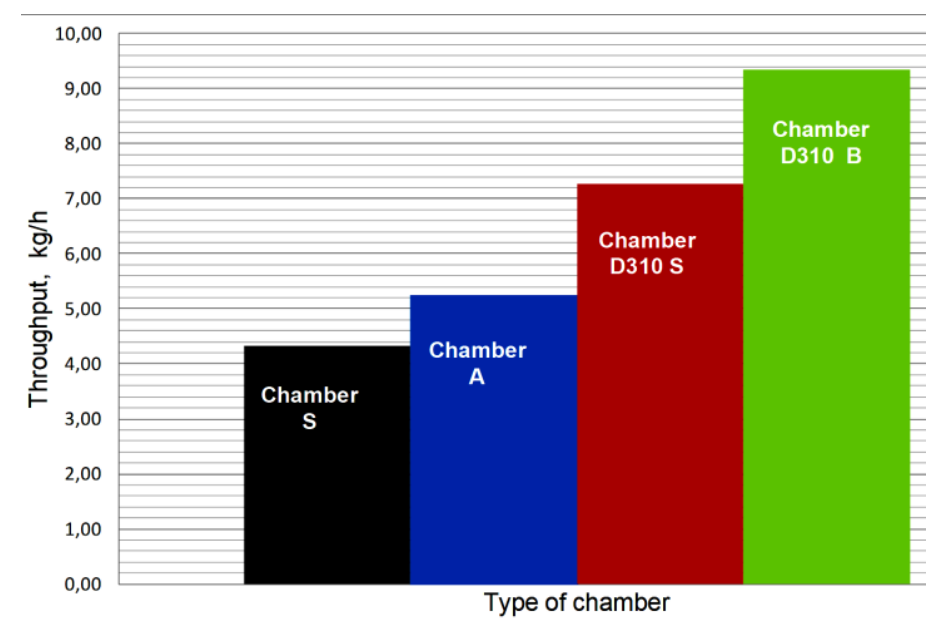

Fig. 7 Influence of the type of chamber used on obtaining the unit capacity of the mill for grain size $d_{50}=10 \mu \mathrm{m}$

Analysis of the results of the milling studies in a vibratory mill with periodic operation:

The grain size control dimension $\mathrm{d}_{50}$ (Figure 5):

- for chamber "A" for the assumed grinding times (5; 10; $20 \mathrm{~min}$ ), the obtained control grains were smaller than in the "S" chamber, respectively by: $40 \%$, $48 \%$, and $58 \%$,

- for the "D310 B" chamber - for the adopted grinding times (5, 10; $20 \mathrm{~min})$, the obtained control grain sizes were smaller than in the "D310 S" chamber, respectively, by: $5 \%, 16 \%$, and $220 \%$.

The grain size control dimension d97 (Figure 4):

- for chamber "A" for the assumed grinding times (5, 10; $20 \mathrm{~min})$, the obtained control grains were smaller than in the "S" chamber, respectively, by: $17 \%$, $26 \%$, and $60 \%$, 
- for the "D310 B" chamber - for the adopted grinding times (5, 10; 20 min), the obtained control grain sizes were smaller than in the "D310 S" chamber, respectively by: $3 \%, 7 \%$, and $31 \%$.

The unit capacity of the mill:

a) The grain size control dimension $\mathrm{d}_{97}=70 \mu \mathrm{m}$ (Figure 6):

- for the "S" chamber a yield of $3.75 \mathrm{~kg} / \mathrm{h}$ was achieved,

- for the "A" chamber, a yield of $46 \%$ more efficiency than in the "S" chamber was obtained,

- for the "D $310 \mathrm{~S}$ " chamber, a yield of 99\% more efficiency than in the "S" chamber was achieved, and $36 \%$ more than in the "A" chamber,

- for the "D310 B" chamber, a yield of $12 \%$ higher efficiency was obtained than in the "D310 S" chamber, 52\% more than in the "A" chamber, and 222\% more than in the "S" chamber.

b) The grain size control dimension $\mathrm{d}_{50}=10 \mu \mathrm{m}$ (Figure 7):

- for the "S" chamber a yield of $4.32 \mathrm{~kg} / \mathrm{h}$ was achieved,

- for the "A" chamber, a yield of $21 \%$ higher efficiency was obtained than in the "S" chamber,

- for the "D 310 S" chamber, a yield of $68 \%$ higher efficiency was achieved than in the "S" chamber, and 39\% more than in the "A" chamber,

- for the "D310 B" chamber, a yield of $29 \%$ higher efficiency was obtained than in the "D310 S" chamber, 78\% higher than in the "A" chamber, and $216 \%$ higher than in the "S" chamber.

\section{EXPERIMENTAL RESEARCH IN A CONTINUOUS VIBRATING MILL}

For the milling studies in a continuous vibratory mill, the technological parameters of the mill were similar to those of the periodical mill (frequency and similar amplitude of vibrations, the degree of filling the chamber with grinding media, a set of grinding media). The vibration amplitude of the chamber was adjusted by choosing the right set of vibrator weights. The efficiency of the mill was treated as the dosing flow of the material into the chamber and then the grain size of the material was tested for different dosing capacities.

The values measured as the criterion for the quality of the milling process were:

- grain size control dimension d97, $\mu \mathrm{m}$,

- grain size control dimension $d_{50}, \mu \mathrm{m}$.

Using the measurement system based on the piezoelectric three-axis acceleration sensor, the vibratory motion parameters of the vibrating chamber were studied. The purpose of these tests was to properly select a set of vibrator weights and to determine the influence of the intensifier element placed inside the chamber on the parameters of the vibrating motion.

No significant influence of the placing inside the chamber on the parameters of the vibrating motion was observed. Figure 8 presents the comparison of vibration trajectories and the time course of displacements for the analyzed axes (in the $\mathrm{XY}$ system) for the "K" and "W" chambers, where blue represents the displacement of the centre of the chamber axis in the vertical direction $(\mathrm{Y})$ and the red colour in the horizontal direction $(X)$. 

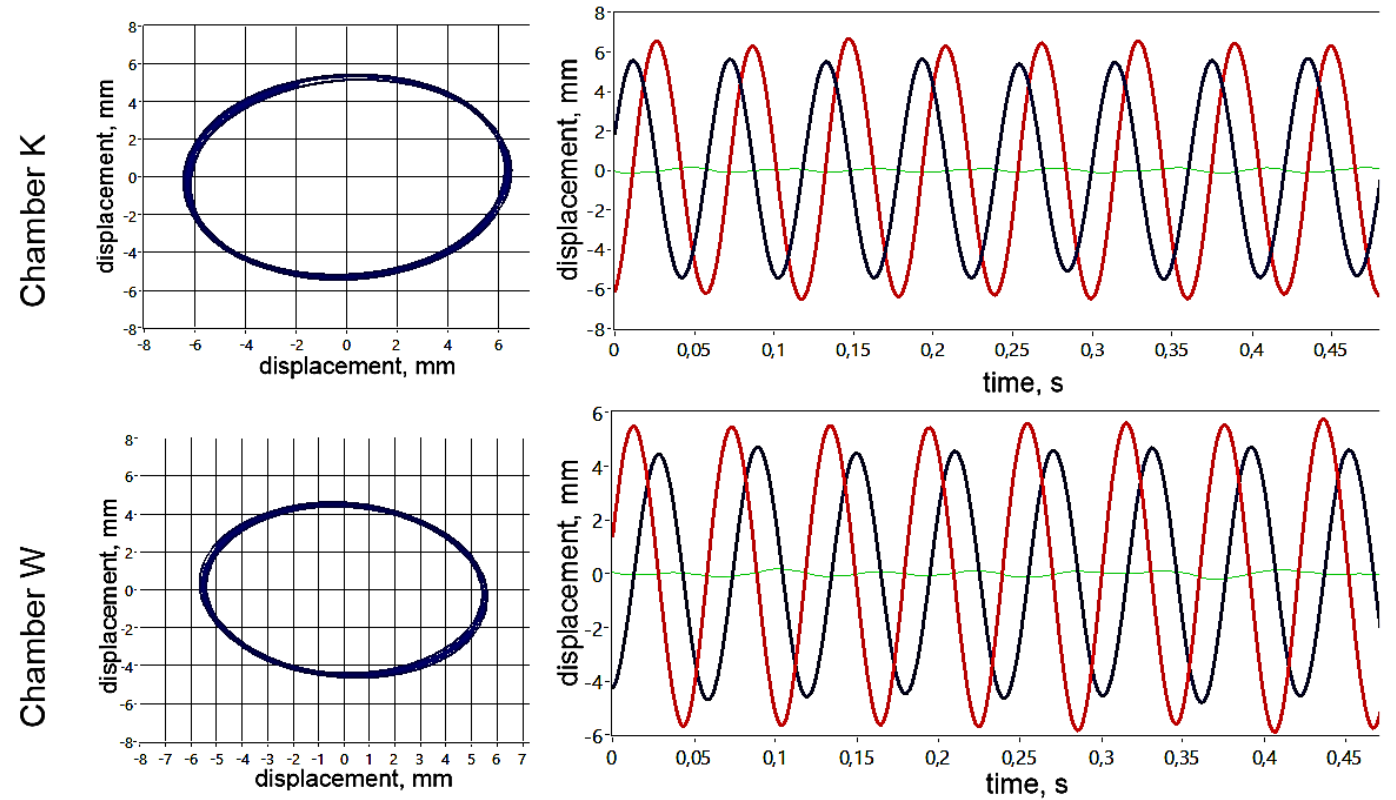

Fig. 8 Trajectory and time characteristics of displacements in the geometrical axis of the chamber depending on the type of chamber used

The influence of the assumed dosing capacities of the material into the mill chamber ( 25 and $12.8 \mathrm{~kg} / \mathrm{h}$ ) on the grain size control dimensions $\mathrm{d}_{97}$ and $\mathrm{d}_{50}$ for the classical chamber ("K"), is shown in Figure 9. The impact of the given parameters on the size of control grains is presented as a function of grinding time - for a continuous mill, this characteristic should be considered in terms of the obtained grain stability of the grinding product over time. On the other hand, the influence of the type of chamber used (classic "K" and the "W" with intensifier element) for higher material dosing capacity into the mill chamber $(25 \mathrm{~kg} / \mathrm{h})$ for the grain size control dimensions $d_{97}$ and $d_{50}$, is presented in Figure 10.

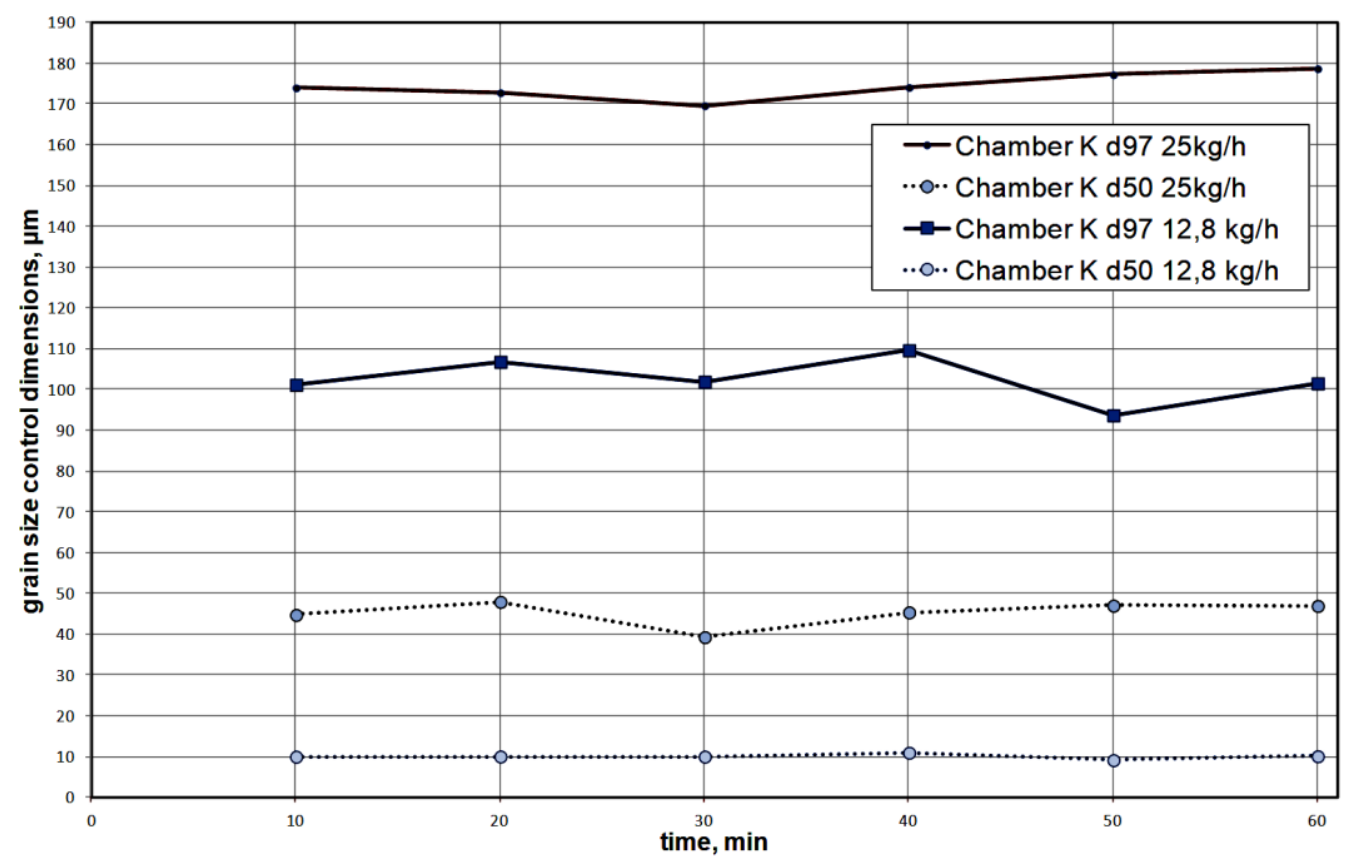

Fig. 9 Effect of the dosing capacity on the grain size control dimensions $d_{97}$ and $d_{50}$ for the chamber of a classical continuous vibratory mill 


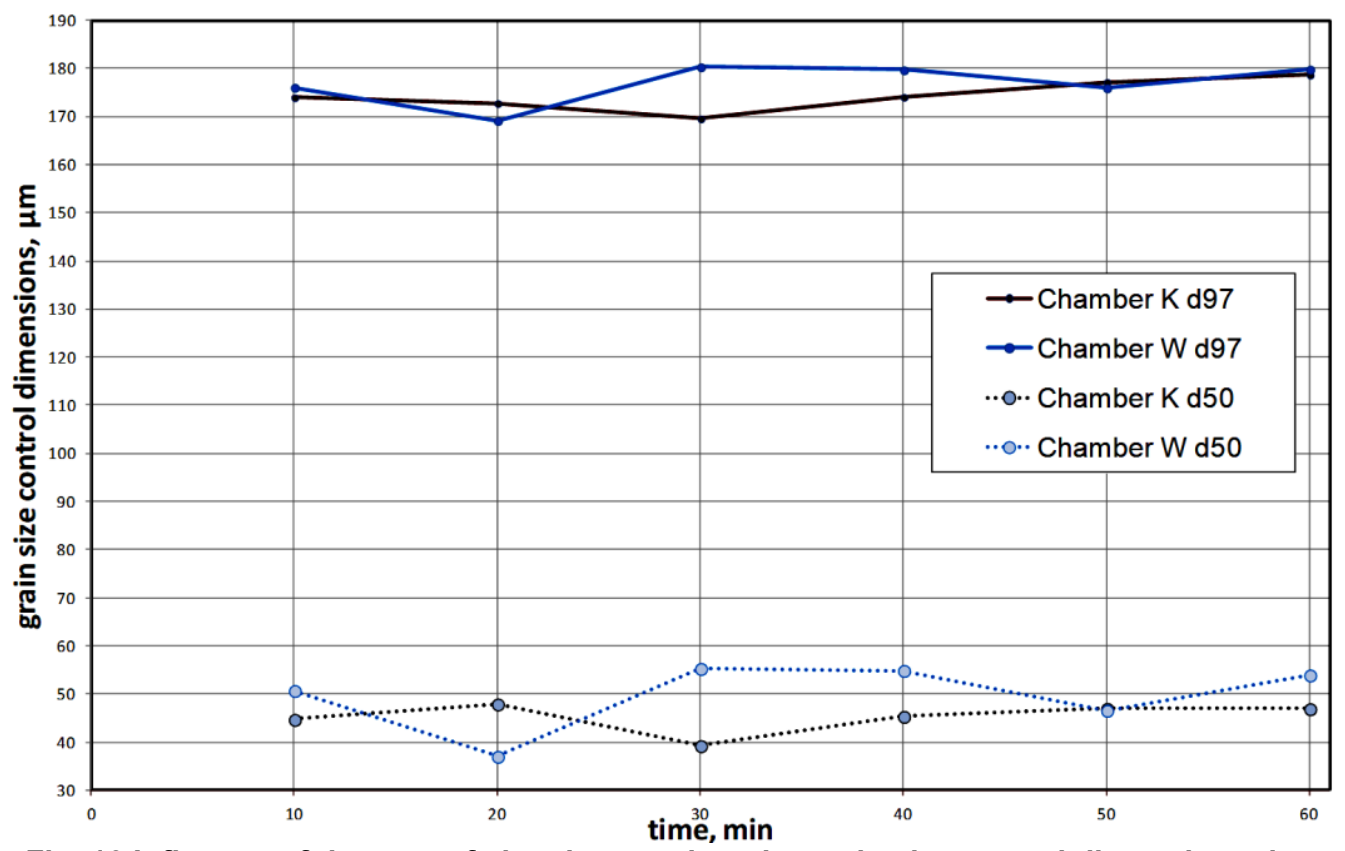

Fig. 10 Influence of the type of chamber used on the grain size control dimensions $\mathrm{d}_{97}$ a nd $d_{50}$ in a continuous vibratory mill - yield $25 \mathrm{~kg} / \mathrm{h}$

Analysis of the results of the milling studies in a continuous vibratory mill: For the "K" chamber of lower dosing capacity $(12.8 \mathrm{~kg} / \mathrm{h})$, the grain size control dimensions d50 were obtained, lower than of higher productivity (25 kg/h) on average by $450 \%$, and the grain size control dimension $\mathrm{d} 97$ lower by an average of $75 \%$ (Figure 9). The application of the element intensifying the milling process ("W" chamber) did not bring the expected result and in comparison to the classical chamber ("K") it improved by a few \% parameters of the analyzed graining or similar or slightly worse graining was obtained (within the measurement error).

\section{CONCLUSIONS}

On the basis of the analysis of the test results, the following conclusions were drawn:

- In the "A" chamber, for each of the analyzed grain size control dimensions, a significant reduction in the size of the control grains of the milling product was obtained from $17 \%$ to $60 \%$ and the yield increased to $46 \%$.

- The use of an element with a diameter of $75 \mathrm{~mm}$ in a chamber with an inner diameter of $310 \mathrm{~mm}$ (chamber "D310 B") resulted in an increase in the unit efficiency of the mill, in comparison to the classical chamber "D310 S", from $12 \%$ (for $d_{97}=70 \mu \mathrm{m}$ ) to $29 \%$ (for $d_{50}=10 \mu \mathrm{m}$ ). Apart from improving the unit efficiency, the use of such an intensifying element significantly improved the parameters of the graining product: $d_{50}$ by as much as $220 \%$, $d_{90}$ and $d_{97}$ by $31 \%$, which confirms the desirability of using this solution in chambers with large internal diameters.

- The milling tests, done in a continuous way with very low milling parameters in the classical chamber and with the intensifying element, has shown the grain size parameters of the milling product are stable over time, and the type 
of chamber used, with determined mill operation parameters, has no significant effect on the grain size parameters of the milling product. Additional continuous milling tests should be carried out in which the focus should be on maintaining a constant fill level of the chamber with ground material - which in the case of quartz sand created great difficulties and could give rise to unsatisfactory test results.

- The use of the intensifying element reduces the amplitude of the vibrations by a few percent in comparison to the classical chamber.

- The milling tests, carried out continuously in a classical chamber at a lower capacity, prove that the fine grinding of quartz sand is possible - with grain size parameters such as in a mill with periodic operation (by a 5-fold smaller chamber volume).

\section{REFERENCES}

Drzymała, Z., Dzik, T., Guzik, J., Kaczmarczyk, S., Kurek, B., Sidor, J. (1992) Badania i podstawy konstrukcji młynów specjalnych. Warszawa: PWN. ISBN 83-0110671-9, 1992 r.

Feliks, J. (2015). Granulation of dolomite and limestone in the vibratory granulator. Przemysl Chemiczny Vol. 94 No. 5, pp. 771-773

Mazur, M. (2017 a), Method of determining the Bond Work Index in vibratory crushing. SGEM 2017 International multidisciplinary scientific geoconference: science and technologies in geology, exploration and mining: 29 June-5 July, 2017, Albena, Bulgaria : conference proceedings Vol. 17 iss. 11, Geology mineral processing, ISBN 978-619-7105-98-8, pp. 903910.

Mazur, M. (2017 b), Possible applications of vibratory technology in crushing technological lines. SGEM 2017 International multidisciplinary scientific geoconference: science and technologies in geology, exploration and mining: 29 June-5 July, 2017, Albena, Bulgaria: conference proceedings. Vol. 17 iss. 11, Geology mineral processing, ISBN 978-619-7105-98-8, pp. 956-972.

Sidor, J. (2005) Basic research, models and engineering design of vibratory mills [in Polish]., UWND AGH, ISSN 0867-6631, Kraków.

Sidor, J., Tomach, P. (2010) Investigation of load movement in a vibratory mill [in Polish]. Ceramic Materials. Vol. 62, No. 4, pp. 601-607.

Sidor, J., Tomach, P. (2011) Preliminary experimental studies of the impact of an additional cylindrical element of the chamber on the intensity of the grinding process in the vibratory mill [in Polish]. Przegląd Górniczy. Vol. 67, No. 11, 2011r., pp. 112-117.

Sidor, J., Tomach, P. (2013) Preliminary experimental studies of the grinding process intensification in a vibratory mill by means of an additional working part installed in the chamber [in Polish]. Ceramic Materials. Vol. 65, No. 2, 2013 r., pp. 140144.

Tomach, P. (2017 a) Study of intensification of the milling process in the vibratory mill [in Polish]. Przemysl Chemiczny, ISSN 0033-2496, Vol. 96 No. 9, pp. 1893-1897.

Tomach, P. (2016) The possibility of milling process intensification in vibratory tube mills by changing their chamber construction. PhD thesis, Kraków.

Tomach, P. (2017 b) The process model of the vibratory mill including the impact of the milling process-intensifying element [in Polish]. PrzemysI Chemiczny, ISSN 00332496, Vol. 96 No. 12, pp. 2467-2470. 
Abstract.

The paper presents the issues related to the grinding process in the vibration mills with low vibration frequency. These mills are rated among devices with high energy of impacts with much wider potential of industrial use than the classic gravitation mills. In vibratory mills there is an unfavorable decrease in the intensity of the grinding process along with the increase in the chamber diameter, which makes it impossible to achieve high performance of such devices. One of the ways to reduce or eliminate this occurrence is to intensify the load movement inside the chamber - this is the subject of this article. The article shows that in a vibrating mill of periodic action it is possible to increase its technological capabilities by application of an appropriate cylindrical component permanently installed inside the milling chamber. The paper also presents an attempt to increase the technological capabilities of a laboratory continuous vibratory mill.

Keywords: mills, vibratory mills, fine grinding, high energy mills 